\title{
USO DA GAMIFICAÇÃO E DE REA'S COMO MÍDIA ADAPTATIVA NO PROCESSO DE ENSINO E APRENDIZAGEM
}

\section{USE OF GAMIFICATION AND REA'S ADAPTATIVE MEDIA IN THE TEACHING AND LEARNING PROCESS}

\author{
Alix Ribeiro da Silva ${ }^{1}$, Mestrando \\ Vania Ribas Ulbricht ${ }^{2}$, D.Sc \\ (1) Universidade Federal de Santa Catarinas - PPGEGC \\ e-mail:alixribeiro@gmail.com \\ (2) Universidade Federal de Santa Catarinas - PPGEGC \\ e-mail: vrulbricht@gmail.com
}

Gamificação. Recursos Educacionais Abertos. Ensino-Aprendizagem. Conhecimento

Este artigo visa abordar o uso da Gamificação e de Recurso Educacional Aberto (REA) no processo de ensino e aprendizagem voltado a formação de conhecimento sobre hábitos sustentáveis de consumo. Para tanto, foi realizado um estudo de pesquisa na literatura sobre tais assuntos a fim de fundamentar a ideia. Gamificação é processo de criação de jogos para aplicação em diferentes áreas de atuação, aproximando de uma realidade da vida diária como forma de motivar e auxiliar na construção do conhecimento. REA são quaisquer materiais de ensino, aprendizado e pesquisa em diferentes suportes ou mídias. Como resultado do estudo, observou-se que as pesquisas e práticas inovadoras de ensino para sustentabilidade por meio de tecnologias ainda é pouco, sendo a educação um meio para prática interdisciplinar com capacidade de tornar as aulas mais atraentes, produtivas e eficientes.

\section{Gamification. Educational Resources Open. Teaching-Learnin. Knowledge}

This article aims to address the use of Gamification and Open Educational Resource (OER) in the teaching and learning process aimed at the formation of knowledge about sustainable habits of consumption. Therefore, a research study was carried out in the literature on such subjects in order to substantiate the idea. Gamification is a process of creating games for application in different areas of activity, approaching a reality of daily life as a way to motivate and assist in the construction of knowledge. REA are any teaching, learning and research materials on different media or media. As a result of the study, it was observed that innovative research and teaching practices for sustainability through technologies is still not enough, with education being a medium for interdisciplinary practice with the capacity to make classes more attractive, productive and efficient. 
$16^{\circ}$ Ergodesign - Congresso Internacional de Ergonomia e Usabilidade de Interfaces Humano Tecnológica: Produto, Informações Ambientes Construídos e Transporte

$16^{\circ}$ USIHC - Congresso Internacional de Ergonomia e Usabilidade de Interfaces Humano Computador

CINAHPA | 2017 - Congresso Internacional de Ambientes Hipermídia para Aprendizagem.

\section{Introdução}

Com a era da globalização a sociedade passou por diversas mudanças decorrentes das Tecnologias da Informação e Comunicação (TIC), quebrando fronteiras entre comunicação e informação. Com o amplo avanço e investimentos em recursos tecnológicos, o cenário educacional passou a sofrer influências que provocam mudanças na forma de agir de professores e estudantes.

Para Zancanaro [2015] o contínuo uso das TIC e a melhoria do acesso à rede de internet têm impulsionado a economia do conhecimento. Isso fez com que a aprendizagem estivesse disponível a qualquer hora e em qualquer lugar, apesar de ser uma aprendizagem linear, de repetição, de comunicação hierárquica e burocratizada [DIVARDIN, 2015]. Paralelamente a isto, o aprendizado está cada vez mais atrelado aos meios digitais de informação e comunicação como a internet, à televisão e recentemente com a Gamificação e com Recursos Educacionais Abertos (REA).

Apesar de exemplos de Gamificação serem corriqueiros em nossas vidas, o termo é considerado novo e em processo de formação. Para Thaler et. al., [2015] o termo é usado como definição de aplicação de elementos, estratégias e pensamentos dos games fora do contexto de um jogo, com finalidade de resolver algum problema. Gamificação é utilizada como uma metodologia a fim de transformar a transmissão do conhecimento e realização de tarefas consideradas difíceis e maçantes em atividades lúdicas e prazerosas, em especial na educação.

Outra realidade que vem transformando as práticas de ensino e aprendizagem são os REA, abordado pela primeira vez em 2002 no Fórum Global de REA, organizado pela UNESCO, que caracteriza um REA como: "materiais de ensino, aprendizado e pesquisa em qualquer suporte ou mídia, que estão sob domínio público, ou estão licenciados de maneira aberta, permitindo que sejam utilizados ou adaptados por terceiros".
De acordo com Lane; Mcandrew [2010] apud Zancanaro [2015] os REA's no início de sua história se apropriaram da ideia de utilização e reutilização de materiais em diferentes contextos de aprendizagem vindas dos Objetos de Aprendizagem, o que foi fundamental para o seu incremento, apesar de ambos os termos serem distintos, sendo na prática o que os diferencia é sua licença de uso.

Entendendo a necessidade de debater sobre sustentabilidade, é que este trabalho busca construir uma saída de aprendizagem lúdica do assunto, através de mídias adaptativas. Através das mídias ou mesmo hipermídias podemos trabalhar com diferentes públicos, inclusive com pessoas com deficiência, haja vista que por vezes este público é excluído das grandes pesquisas e da usabilidade de projetos sem ergonomia e inacessíveis.

\section{Metodologia}

Para desenvolvimento deste trabalho, foi adotada uma abordagem de pesquisa qualitativa. Para Gerhardt e Silveira [2009] essa abordagem não se preocupa com representatividade numérica, mas sim, com o aprofundamento da compreensão de um conteúdo, na qual se demonstra a variedade de perspectivas sobre o objeto, sendo predominante focado na descrição [MARTINS; THEÓPHILO, 2007]. Apoiado em tal metodologia é "necessário que o pesquisador entre em contato direto com o ambiente no qual o fenômeno está inserido" [MARTINS; THEÓPHILO, 2007]. Tal estudo também é de cunho exploratório, na medida em que objetivo ter maior familiaridade com o problema, com vistas a torná-lo mais visível e, posteriormente, construir hipóteses, baseada principalmente em uma realidade.

\section{Contexto da área}

Podemos relacionar os REA e a Gamificação como mídias adaptativas de propagação do conhecimento. Nos tempos atuais, o conhecimento tem sido reconhecido como entidade de valor necessário para o sucesso das organizações, sendo as mídias estratégias para diversificar os recursos
Realização:

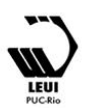




\section{$16^{\circ}$ \\ ERGODESIGN USIHC CINAHPA}

$16^{\circ}$ Ergodesign - Congresso Internacional de Ergonomia e Usabilidade de Interfaces Humano Tecnológica: Produto, Informações Ambientes Construídos e Transporte

$16^{\circ}$ USIHC - Congresso Internacional de Ergonomia e Usabilidade de Interfaces Humano Computador

CINAHPA | 2017 - Congresso Internacional de Ambientes Hipermídia para Aprendizagem. educacionais na perspectiva de contemplar os diversos estilos de aprendizagem [LEDO, 2016].

Setton [2011] entende o conceito de mídia como algo abrangente, referindo-se a elas como os meios de informação e comunicação massivos dedicados, em especial ao entretenimento, lazer, informação e aprendizado, podendo ser por meio do rádio, televisão, jornal, livro, fotografia e mesmo os jogos digitais ou analógicos, e os sistemas que agrupam a informática, a TV e as telecomunicações computadores e redes de comunicação [SETTON, 2011].

Para Dutra [2007] as mídias de REA contemplam os diferentes conteúdos de aprendizagem, entre esses: cursos online, objetos de aprendizagem e etc.. Os REA incluem também ferramentas para apoiar o desenvolvimento, uso, reuso, busca e organização de conteúdo, bem como sistemas de gerenciamento de aprendizagem e ferramentas de autoria.

Banzato [2012] apud Zancanaro [2015] os REA se baseiam em três princípios: os materiais devem ter valor educacional; deve ser totalmente aberto, sem custos ou qualquer restrição, disponível para reutilização, revisão e redistribuição; e as tecnologias devem ser capazes de dar suporte ao desenvolvimento e às questões pedagógicas dos REA.

Outro ponto a se destacar quanto aos REA é o tratamento do termo conhecimento, que passa a ser entendido como um bem público da humanidade, que não surge apenas das TIC's, ou das diferentes mídias de propagação de informação de maneira aberta ou livre. Rossini [2010] entende que a filosofia dos REA representa uma escolha clara de indivíduos e instituições, considerando a abertura ou liberdade de uso como uma atitude, a qual corresponde à mesma atitude que marcou os originais pensadores e desenvolvedores da internet, e que também permeia os ideais do software livre, como é o caso do Linux.

Gamificação para Junior [2014], é um processo que usa elementos, mecânicas e dinâmicas de jogos para engajar e direcionar comportamentos de jogadores dentro de um contexto de não jogo, transformando a prática através do conhecimento com o auxílio de uma mídia. Para Schreiber et. Al., [2000] apud Ledo [2016] a vida social está cada vez mais direcionada no conhecimento. Sendo o conhecimento uma necessidade de valor para sociedade dos nativos digitais, ou seja, daqueles nascidos conectados as diferentes mídias ou TIC. Para entender, explicitar, sistematizar e incorporar conhecimento dentro das instituições de ensino seja de caráter público ou privado torna-se essencial para o progresso e desenvolvimento das relações humanas a partir da sabedoria [LEDO, 2016], sendo a Gamificação um grande aliado para o processo de ensino e aprendizagem nas escolas.

Do ponto de vista do conhecimento, a educação até recentemente era vista como algo que se desenvolvia somente nas salas de aula, onde o professor era o "dono do conhecimento"; contudo, com os avanços e facilidades ao uso das mídias, tal pensamento tornou-se defasado, sendo para Reinehr [2012] apud Zancanaro [2015], as escolas por sua vez, "[...] não tem mais o monopólio do conhecimento" e o indivíduo vê na internet a possibilidade de acessar uma grande quantidade de informações, o que torna a tecnologia um agente transformador da sociedade.

Para Junior [2014] a escola precisa acompanhar as mudanças na sociedade. Mesmo sem perceber, quase tudo é Gamificado, ou seja, tem uma linguagem dinâmica, divertida e prazerosa. Os jogos são o passatempo preferido da humanidade, e os REA estão para alavancar o conhecimento e o processo de ensino e aprendizagem.

Gamificação na educação deve ser visto como um fenômeno emergente com potencialidades de aplicação em diferentes áreas. Um foco interdisciplinar a ser estudado é a respeito do conhecimento sobre hábitos sustentáveis de consumo em ambiente residencial [JAPPUR et. Al. 2014].

A Gamificação encontra na educação escolar um solo bastante fértil para a sua aplicação, pois na escola atual encontram-se os indivíduos que carregam consigo os conhecimentos advindos das
Realização:

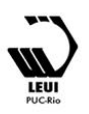


interações com os games e com os REA.

\section{Conhecimento}

Davenport; Prusak [1998] apud Ledo [2016] ressalta que o conhecimento é uma mistura fluida de experiência estruturada, valores, informação contextual e discernimento especializado que fornece um parâmetro para avaliar e incorporar novas experiências em informação.

Nonaka; Takeuchi [1997] falam do conhecimento tácito ou explícito, sendo o tácito um

conhecimento da mente e do corpo. E o conhecimento explícito é codificado, sendo reduzido a escrito, desenhos ou programas de computador.

A partir do uso da Gamificação e dos REA cria-se novos conhecimentos, surgindo novos desafios de compartilhamento de conhecimento. Segundo Nonaka e Takeuchi [1997] o conhecimento é criado a partir de uma conversão de conhecimento, existindo quatro modos: socialização;

externalização; combinação e internalização.

O compartilhamento do conhecimento na escola através da Gamificação e dos REA quebrou o paradigma de que o ensino devia ser exclusivo da sala de aula, necessitando de avanços em inclusão digital e atualização das estratégias educacionais dos professores para uso das TIC.

Os jogos digitais educacionais e os REA possibilitam o amplo compartilhamento do conhecimento, envolvendo o educando na aprendizagem, assim elevando a motivação no aprendizado. A inovação no ensino por meio das novas tecnologias, que combine ensino com diversão, sem perder o foco na aprendizagem, mostra-se vital para a sociedade aprendente.

\section{Forma Interdisciplinar para Trabalhar}

Repko [2011] considera a interdisciplinaridade como "um processo de responder a uma questão, resolução de um problema ou abordagem de um tema que é muito amplo ou complexo para ser tratado de forma adequada por uma única $16^{\circ}$ Ergodesign - Congresso Internacional de Ergonomia e Usabilidade de Interfaces Humano Tecnológica: Produto, Informações Ambientes Construídos e Transporte

$16^{\circ}$ USIHC - Congresso Internacional de Ergonomia e Usabilidade de Interfaces Humano Computador

CINAHPA | 2017 - Congresso Internacional de Ambientes Hipermídia para Aprendizagem. disciplina ou profissão".

Ainda segundo Repko [2011] a interdisciplinaridade é orientada a problemas, sendo sua abordagem concentrada em pesquisa, suprimento, e na resolução de problemas práticos como resposta às demandas externas da sociedade. No contexto de interdisciplinaridade, a integração é o processo pelo qual ideias, dados e informações, métodos, ferramentas, conceitos, e ou teorias de duas ou mais disciplinas são sintetizadas, conectadas, ou misturadas [REPKO, 2011].

Atualmente as TIC's estão presentes em quase todos os espaços da sociedade, sendo a escola um espaço propício para o uso das tecnologias em auxílio do ensino e aprendizagem. Para Audino e Nascimento [2010] estamos em um momento em que a informática e, em especial a internet, constitui-se numa realidade sem volta, reconfigurando nosso cotidiano, necessitando práticas interdisciplinares. O professor deve se apropriar das tecnologias, "descobrindo as possibilidades de uso que ela permite na aprendizagem do aluno, favorecendo, o repensar do ato de ensinar" [SODRÉ; HORA, 2014 apud MIYAZAWA et. Al., 2016].

Um desafio interdisciplinar a enfrentar na escola e na sociedade, é a respeito da cultura da sustentabilidade, especificamente para o ambiente residencial, caracterizando-se pelos hábitos de consumo e produção humana. Jappur et. Al., [2014] diz que a cultura da sustentabilidade está vinculada a diversos ambientes gerados em edificações, como: produção de resíduos sólidos e líquidos, e o consumo de energia e água. Para Rodrigues e Colesanti [2008] o uso das TIC's com enfoque em educação ambiental representa um avanço, pois pela "integração da informática e das mídias pode haver a sensibilização e o conhecimento dos ambientes e dos seus problemas intrínsecos".

A escola precisa criar novas formas de entender as representações socioambientais, de pensar e viver as relações com o planeta, o ambiente natural, social, econômico e cultural [POLLI; SIGNORINI, 2012 apud MIYAZAWA et. Al., 2016]. Agregar
Realização:
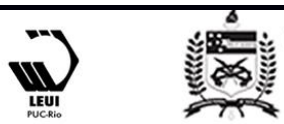
$16^{\circ}$ Ergodesign - Congresso Internacional de Ergonomia e Usabilidade de Interfaces Humano Tecnológica: Produto, Informações Ambientes Construídos e Transporte

$16^{\circ}$ USIHC - Congresso Internacional de Ergonomia e Usabilidade de Interfaces Humano Computador

CINAHPA | 2017 - Congresso Internacional de Ambientes Hipermídia para Aprendizagem. isso com o uso das TIC's com foco interdisciplinar, pode contribuir para despertar o interesse dos educandos.

\section{Desafios para o Desenvolvimento do Trabalho}

Hoje vivemos em uma cultura meramente midiática, onde a comunicação e educação giram em torno das tecnologias digitais e das mídias. Nisso, podemos dizer que a informação está generalizada e a cultura predominante em todas as esferas da vida social é meramente midiática; deixando a desejar e duvidar por muitos, que veem as mídias como forma de barreira na comunicação, pela percepção que as mídias servem, mais para emitir comunicado do que para comunicar [OROFINO, 2005].

A escola, assim como a sociedade em geral deve perceber as mídias neste trabalho proposto e os seus desafios de aplicações frente a uma sociedade cada vez mais constituída em rede [CASTELLS, 1999 apud SOUZA, 2002]. A partir da análise do processo de revolução tecnológica é possível observar que estamos entrando na era da informação, onde o conhecimento será um bem mais importante do que os meios de produção [SOUZA, 2002].

\section{Considerações}

Ao concluir este trabalho, pude perceber que diante da sociedade em rede e da era da informação, é indiscutível o fato de que as TIC's configuram-se como importante difusor da Gamificação e dos REA e seus repositórios, da EaD, dos AVA, dentre outros recursos que podem ser usados como auxílio no processo de ensino e aprendizagem na educação.

Percebe-se que nos últimos anos está surgindo um grande foco nas mídias e nos projetos de universidades sendo aplicadas a educação no processo de ensino e aprendizagem, como também, aplicações de recursos tecnológicos, devido ao rápido desenvolvimento das TIC's, como é o caso do Laboratório de Mídia e Conhecimento LabMídia, no Campus da UFSC em Araranguá, com o objetivo de alicerçar ações de fomento à produção midiática.

Apesar da aplicação da Gamificação no ambiente escolar ser uma estratégia para melhorar o ensino e aprendizagem, é necessário se ter cuidado com o que se chama de "jogos digitais" Gamificado, pois, nem todo jogo na escola é educativo e parte do princípio de Gamificação. O mesmo cuidado deve ser encarado pelos REA, que têm o desafio de algumas imposições para sua aplicação, que segundo Santana et. al., [2012] são a necessidade de: a) reforma da Lei dos Direitos Autorais ( $n^{\circ}$ 9610/1998), no sentido de estabelecer limitações e exceções relacionadas aos usos educacionais; $b$ ) criação de uma política de inclusão digital nas escolas, para que estudantes e professores possam se tornar desenvolvedores de REA e não somente meros consumidores; c) ampliação da formação de professores para elaboração, uso e reuso de REA.

A escola necessita de novas maneiras de ensino para dar conta dos educandos que estão inseridos no contexto das mídias e das tecnologias digitais e encontram-se desinteressados pelos métodos de ensino e aprendizagem aplicados atualmente.

Por fim, os maiores desafios estarão na aplicação de jogos digitais lúdicos e no uso de REA's nas escolas, haja vista que jogos são poucos ou quase nunca utilizados em prol do ensino na educação, sendo desafiado a quebrar barreirar e gerar oportunidades para formação da cultura da sustentabilidade através dos recursos tecnológicos estudados.

\section{REFERÊNCIA BIBLIOGRÁFICA}

AUDINO, D. F.; NASCIMENTO, R. S. Objetos de aprendizagem, diálogos entre conceitos e uma nova proposição aplicada à educação. Revista Contemporânea de Educação, Disponível em: <https://revistas.ufrj.br/index.php/rce/article/ view/1620/1468 >. Acesso em: 20 out. 2016.

DIVARDIN, D. Tecnologias na educação: os recursos educacionais abertos configurando novas práticas educacionais. Disponível em:

<http://www.rio2015.esocite.org/resources/anais/5/
Realização:
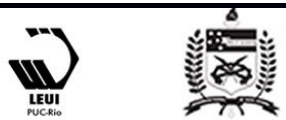


\section{$16^{\circ}$ \\ ERGODESIGN USIHC CINAHPA}

$16^{\circ}$ Ergodesign - Congresso Internacional de Ergonomia e Usabilidade de Interfaces Humano Tecnológica: Produto, Informações Ambientes Construídos e Transporte

$16^{\circ}$ USIHC - Congresso Internacional de Ergonomia e Usabilidade de Interfaces Humano Computador

CINAHPA | 2017 - Congresso Internacional de Ambientes Hipermídia para Aprendizagem.
1440633988_ARQUIVO_esocite_completo1.pdf>. Acesso em 17 out. 2016.

DUTRA, R. L. de S; TAROUCO, L. M. R. h. Recursos Educacionais Abertos. Centro Interdisciplinar de Novas Tecnologias da Educação da UFRGS, 2007.

\section{GERHARDT, T. E, SILVEIRA, D. T. Métodos} de pesquisa. Universidade Aberta do Brasil UAB/UFRGS. Curso de Graduação Tecnológica Planejamento e Gestão para o Desenvolvimento Rural da SEAD/UFRGS. - Porto Alegre: Editora da UFRGS, 2009.

JAPPUR, R. F.; FORCELLINI, F. A.; SPANHOL, F. J. Modelo conceitual para jogos educativos. Disponível em: < http://revistas.ufpr.br/atoz/article/ view/41344/25351 >. Acesso em 18 out. 2016.

JUNIOR, S. A. S. Gamificação: Introdução e conceitos básicos. Ebook - 2014. Contatos para acesso: silvio@gamificando.com.br.

LEDO, R. Z. Modelo de identificação do conhecimento procedimental de alto desempenho para atividade de modelagem digital 3D. Tese de Doutorado PPMS - UFSC, 2016. Disponível em: < http://btd.egc.ufsc.br/wpcontent/uploads/2016/08/Rafael-ZanelatoLedo.pdf>. Acesso em: 21 out. 2016.

MARTINS, G.A.; THEÓPHILO, C.R. Metodologia da investigação científica para ciências sociais aplicadas. São Paulo: Atlas, 2007

SOUZA, M. V. Redes informatizadas de comunicação: a teia da rede internacional DPH. Tese de Doutorado, 2002. Disponível em: <https://repositorio.ufsc.br/xmlui/handle/12345678 9/84042>. Acesso em: 22 out. 2016.

MIYAZAWA, G. C. M. C.; SIQUEIRA, A. C.; JÚNIOR, C. F. A.; FRENEDOZO, R. C. Aplicativos para o Ensino-Aprendizagem de Educação Ambiental. Disponível em: <http://www.latec.ufrj.br/revistas/index.php?journa l=eduambiental \&page $=$ article\&op=view\&path $\% 5 \mathrm{~B} \% 5 \mathrm{D}=795>$.
Acesso em: 21 out. 2016

NONAKA, I.; TAKEUCHI, H. Criação de conhecimento na empresa: como as empresas japonesas geram a dinâmica da inovação. Rio de Janeiro: Campus, 1997.

OROFINO, M. I. Mídias e mediação escolar, pedagogias do meio, participação e visibilidade. São Paulo, Ed. Cortez: Instituto Paulo Freire, 2005.

RODRIGUES, G. S. S. C.; COLESANTI, M. T. Educação ambiental e as novas tecnologias de informação e comunicação. 2008. Disponível em: $<$

http://www.scielo.br/pdf/sn/v20n1/a03v20n1.pdf >. Acesso em: 21 out. 2016.

ROSSINI, C. Aprendizagem digital, recursos educacionais abertos e cidadania. In: Cidadania e redes digitais. Sergio Amadeu da Silveira, organizador. São Paulo: Comitê Gestor da Internet no Brasil: Maracá, Educação e Tecnologias, 2010.

SANTANA, B.; ROSSINI, C.; PRETTO, N. L. Recursos educacionais abertos: práticas colaborativas e políticas públicas. 2012. Disponível em: <http://www.livrorea.net.br/livro/livroREA1edicao-mai2012.pdf >. Acesso em: 21 out. 2016.

SETTON, M. da G. Mídia e educaçãa. 1 edição, São Paulo. Ed. Contexto, 2011.

REPKO, A. F. Interdisciplinary Research: Process and Theory. SAGE Publications, 2011. ISBN 9781412988773. Disponível em: <https://books.google.com.br/books?id=I0PiSIgmp 38C >. Acesso em: 21 out. 2016.

THALER, A.; GONÇALVES, B.; FIALHO, F.; JÚNIOR, J. E. S; TRISKA, R. A Gamificação Aplicada à Educação e ao Engajamento. Anais do $5^{\circ}$. Congresso Internacional de Conhecimento e Inovação (CIKI). Disponível em: <http://www.congresociki.org/wpcontent/uploads/2016/02/Anais-CIKI-2015volume-2.pdf>. Acesso em: 19 out. 2016.
Realização:

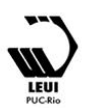


$16^{\circ}$ USIHC - Congresso Internacional de Ergonomia e Usabilidade de Interfaces Humano Computador

\section{ZANCANARO, A. Produção de recursos}

educacionais abertos com foco na disseminação

do conhecimento: uma proposta de framework.

Tese de Doutorado em EGC - UFSC, 2015.

Disponível em: < http://btd.egc.ufsc.br/wp-

content/uploads/2015/06/Airton-Zancanaro.pdf >.

Acesso em 19 out. 2016.

\section{Agradecimentos}

Agradeço em especial aos mestres do saber que fazem parte do time do Programa de PósGraduação em Engenharia e Gestão do Conhecimento (PPGEGC), que direta ou indiretamente contribuem com a nossa formação de pesquisadores, em especial a minha orientadora por todo seu empenho. Não podia perder a oportunidade de agradecer a Coordenação de Aperfeiçoamento de Pessoal de Nível Superior (CAPES) por todo fomento à pesquisa das Universidades Brasileiras. 